\title{
PENGARUH HIPERKOAGULASI TERHADAP MORTALITAS ASTROSITOMA PADA PEMANTAUAN 12 BULAN
}

\author{
EFFECT OF HYPERCOAGULABILITY TO ASTROCYTOMA MORTALITY WITHIN \\ 12-MONTHS OF FOLLOW UP
}

Among Wibowo, * Tiara Aninditha, ** Henry Riyanto Sofyan, ** Rini Andriani***

\begin{abstract}
Introduction: Astrocytoma is the most common primary brain tumor. Hypercoagulable state is one of brain tumor complications which can cause vein thromboembolism (VTE). Vein thromboembolism incidence is increased in astrocytoma patients. Hypercoagulable state in astrocytoma could lower patient's survival.

Aim: To investigate the effect of hypercoagulable state on mortality within 12 months of follow up in astrocytoma patients.

Methods: This study design was retrospective cohort. This research data was taken from medical records in Cipto Mangunkusumo General Hospital and Dharmais Cancer Center Hospital on December 2017-February 2018. The subjects were adult astrocytoma patients who had histopathology and hemostasis examination. The variables investigated in this study were gender, age, prothrombin time (PT), activated partial thromboplastin time (aPTT), and D-dimer. Data processed descriptively and analytically using SPSS ver. 20 for Windows.

Results: There were 49 subjects in this research. Around 30 (61.2\%) subjects were men and 20 (40.8\%) subjects aged $>50$ years old. High grade glioma was found in 39 (79.6\%) subjects and hypercoagulable state was found in 34 $(69.4 \%)$ subjects. There were 20 subjects deceased in 12-month follow-up. Subjects with hypercoagulable state had relative risk (RR) of 3.97 more susceptible to die in 12-month follow-up compared to control $(p=0.009)$.
\end{abstract}

Discussion: Hypercoagulation was a mortality risk factor in 12-month follow-up in patients with astrocytoma.

Keywords: Astrocytoma, hypercoagulation, mortality within 12-months of follow up

\section{ABSTRAK}

Pendahuluan: Astrositoma merupakan tumor otak primer yang paling sering ditemukan. Salah satu komplikasi dari tumor otak adalah keadaan hiperkoagulasi. Keadaan hiperkoagulasi dapat menyebabkan tromboemboli vena. Insiden tromboemboli vena meningkat pada astrositoma. Keadaan hiperkoagulasi pada astrositoma dapat menurunkan kesintasan atau meningkatkan mortalitas pada pasien astrositoma.

Tujuan: Mengetahui pengaruh hiperkoagulasi pada mortalitas pasien astrositoma dalam 12 bulan pemantauan.

Metode: Penelitian kohort retrospektif terhadap pasien tumor otak jenis astrositoma yang dirawat oleh Divisi Neuroonkologi di RSUPN Dr. Cipto Mangunkusumo (RSCM) dan RS Pusat Kanker Dharmais (RSKD) pada bulan Desember 2017 hingga Februari 2018. Sumber data adalah data sekunder berupa rekam medis pasien dewasa yang telah memiliki hasil pemeriksaan histopatologis dan hemostasis. Variabel yang diambil dalam penelitian ini adalah jenis kelamin, usia, prothrombin time (PT), activated partial thromboplastin time (aPTT), dan D-dimer. Data diolah secara deskriptif dan analitik bivariat menggunakan SPSS ver. 20 for Windows.

Hasil: Terdapat 49 subjek dalam penelitian ini yang mayoritas $(61,2 \%)$ laki-laki, berusia $<50$ tahun $(59,2 \%)$, dan memiliki jenis high grade gliomas (75,8\%). Sebagian besar subjek mengalami hiperkoagulasi $(69,4 \%)$ dan dalam kondisi hidup $(59,2 \%)$ pada 12 bulan pascaperawatan. Subjek dengan hiperkoagulasi memiliki risiko relatif (RR) 3,97 kali lebih rentan mengalami kematian setelah 12 bulan dibandingkan kontrol $(\mathrm{p}=0,009)$.

Diskusi: Hiperkoagulasi merupakan salah satu faktor risiko kematian dalam 12 bulan pada pasien astrositoma.

Kata kunci: Astrositoma, hiperkoagulasi, mortalitas 12 bulan

*FK Universitas Lambung Mangkurat, Banjarmasin; **Departemen Neurologi FK Universitas Indonesia/RSUPN Dr. Cipto Mangunkusumo, Jakarta, ***SMF Neurologi RS Pusat Kanker Dharmais, Jakarta. Korespondensi: amongwi@yahoo.com.

\section{PENDAHULUAN}

Glioma merupakan tumor otak primer yang paling banyak ditemukan. Angka kejadian glioma adalah sekitar 5,5 per 100.000 penduduk. Berdasarkan klasifikasi histopatologinya, glioma terdiri dari astrositoma, oligodendroglioma, dan ependimoma. ${ }^{1-2}$ Data Departemen Neurologi FKUI/RSUPN Dr. Cipto
Mangunkusumo (RSCM) menunjukkan pasien tumor otak primer selama tahun 2011-2015 memiliki rerata usia 48 (18-74) tahun dengan mayoritas tumor primer otak yang dijumpai adalah astrositoma $(47 \%){ }^{3}$

Median kesintasan pasien glioma derajat tinggi atau high grade glioma (HGG) menurut Nayak dkk pada pasien glioblastoma multiform (GBM) 
berdasarkan WHO grade IV adalah sekitar 16-18 bulan. Pasien dengan astrositoma anaplastik (WHO grade III) memiliki median kesintasan sekitar 2-5 tahun, ${ }^{1}$ sedangkan pada astrositoma derajat rendah (WHO derajat II) atau low grade glioma (LGG) mencapai 10-14 tahun. ${ }^{4}$

Salah satu komplikasi yang sering ditimbulkan pada tumor otak adalah keadaan hiperkoagulasi. Keganasan menyebabkan gangguan hemostasis pada 90\% pasien dan merupakan komplikasi penyebab kematian terbanyak kedua setelah keganasan tersebut. Penelitian Budikayanti dkk di Departemen Neurologi FKUI/RSCM menemukan 93\% pasien dengan tumor di susunan saraf pusat (SSP) mengalami keadaan status hiperkoagulasi. ${ }^{5}$ Penelitian sebelumnya yang dilakukan oleh Tunjungsari dkk pada tahun 2016 mengenai profil koagulasi pada tumor otak primer dan tumor otak sekunder menunjukkan koagulopati pada $79,4 \%$ subjek. $^{5}$

Beberapa penelitian sebelumnya menunjukkan kaitan antara tumor otak primer dengan gangguan koagulasi, khususnya kelompok astrositoma. Hal ini diduga akibat astrosit merupakan salah satu jenis sel yang kaya akan tissue factor (TF), salah satu komponen utama dalam aktivasi kaskade koagulasi. Penelitian Eddleston dkk pada tikus percobaan menunjukkan bahwa astrosit merupakan sumber TF utama di susunan sarafpusat. Inflamasi terinduksi oleh astrositosis dapat menyebabkan peningkatan kadar TF. Dengan demikian, diduga bahwa multiplikasi sel astrosit pada astrositoma dapat meningkatkan kadar TF dan menyebabkan gangguan koagulasi. ${ }^{4-5}$ Pasien GBM memiliki risiko mengalami komplikasi lebih besar mengalami tromboemboli vena dibanding pasien pada umumnya. ${ }^{6}$

Komplikasi tromboemboli vena dapat memengaruhi kesintasan pasien. Dalam telaah sistematisnya, Renni dkk menemukan bahwa keadaan hiperkoagulasi merupakan faktor prediktor luaran buruk kesintasan pasien. ${ }^{7}$ Penelitian Semrad dkk menunjukkan bahwa pasien astrositoma yang mengalami venous thromboemboli (VTE) memiliki angka kematian 30\% lebih tinggi dibandingkan kontrol. ${ }^{8}$ Namun, belum ada penelitian mengenai pengaruh keadaan hiperkoagulasi terhadap mortalitas pasien astrositoma, sehingga perlu dilakukan penelitian ini.

\section{TUJUAN}

Mengetahui pengaruh hiperkoagulasi pada mortalitas pasien astrositoma dalam pemantauan 12 bulan.

\section{METODE}

Penelitian ini merupakan penelitian kohort retrospektif menggunakan data sekunder berupa rekam medis pasien astrositoma yang dirawat oleh Divisi Neuroonkologi di RSCM dan RS Pusat Kanker Dharmais (RSKD) pada bulan Desember 2017Februari 2018. Kriteria inklusi adalah pasien berusia 18 tahun, terdapat hasil pemeriksaan histopatologis, dan telah dilakukan pemeriksaan laboratorium hemostasis. Subjek dieksklusi jika hamil, sepsis, memiliki kelainan perdarahan, dan tidak dapat dihubungi setelah 12 bulan.

Dilakukan pencatatan data derajat astrositoma, prothrombin time (PT), activated partial thromboplastin time (aPTT), D-dimer, dan mortalitas pada 12 bulan pascaperawatan di RS. Penelitian Tunjungsari mengkaji PT, aPTT, dan D-dimer sebagai penanda hiperkoagulasi pada tumor otak primer dan sekunder. ${ }^{5}$ Keadaan hiperkoagulasi ditandai dari pemendekan PT atau pemendekan aPTT atau peningkatan D-dimer. PT dan aPTT dianggap memendek jika rasio PT atau APTT $<0,8$ terhadap kontrol. D-dimer dianggap meningkat jika $>300 \mu \mathrm{g} / \mathrm{L}$ atau $>500 \mathrm{ng} / \mathrm{MI}$ sesuai dengan nilai rujukan masingmasing laboratorium.

Data dari penelitian diolah menggunakan SPSS ver. 20 for Windows serta disajikan secara deskriptif dan analitik. Uji Chi-square dilakukan untuk melihat hubungan antara hiperkoagulasi dengan mortalitas dalam pemantauan 12 bulan. Jika syarat uji Chisquare tidak terpenuhi akan dilakukan uji Fisher. Nilai $p$ dianggap bermakna bila $\mathrm{p}<0,05$.

\section{HASIL}

Didapatkan 49 subjek (Tabel 1) yang mayoritas laki-laki $(61,2 \%)$, berusia $<50$ tahun $(59,2 \%)$, dan memiliki jenis high grade gliomas $(75,8 \%)$. Sebagian 
besar subjek mengalami hiperkoagulasi (69,4\%) dan dalam kondisi hidup $(59,2 \%)$ pada 12 bulan pascaperawatan.

Tabel 1. Karakteristik Demografi Subjek $(n=49)$

\begin{tabular}{ll}
\hline \multicolumn{1}{c}{ Karakteristik } & n (\%) \\
\hline Jenis Kelamin & \\
- Laki laki & $30(61,2)$ \\
- Perempuan & $19(38,8)$ \\
Rentang Usia \\
- $18-50$ tahun \\
- >50 tahun \\
Jenis Tumor \\
- Low grade \\
- High grade & $29(59,2)$ \\
Hiperkoagulasi & $20(40,8)$ \\
- Ya & \\
- Tidak & $10(20,4)$ \\
Kondisi & $39(79,6)$ \\
- Mati & \\
- Hidup & $34(69,4)$ \\
\hline
\end{tabular}

Tabel 2 menunjukkan hubungan yang bermakna antara kelompok usia dan jenis tumor dengan kejadian hiperkoagulasi. Subjek dengan usia $>50$ tahun dan jenis tumor high grade lebih cendrung untuk menyebabkan keadaan hiperkoagulasi $(p=0,009$ dan $\mathrm{p}=0,033$ ).

Tabel 2. Hubungan antara Hiperkoagulasi dengan Jenis Kelamin, Kelompok Usia, dan Jenis Tumor ( $(\mathrm{n}=49)$

\begin{tabular}{|c|c|c|c|c|}
\hline \multirow[b]{2}{*}{ Variabel } & \multicolumn{2}{|c|}{ Hiperkoagulasi } & \multirow[b]{2}{*}{$\begin{array}{l}\text { Total } \\
\text { n (\%) }\end{array}$} & \multirow[b]{2}{*}{$\mathbf{p}^{*}$} \\
\hline & $\begin{array}{c}\text { Ya } \\
\text { n }(\%)\end{array}$ & $\begin{array}{c}\text { Tidak } \\
\text { n (\%) }\end{array}$ & & \\
\hline $\begin{array}{l}\text { Jenis Kelamin } \\
\text { - Laki laki } \\
\text { - Perempuan }\end{array}$ & $\begin{array}{l}20(58,8) \\
14(41,2)\end{array}$ & $\begin{array}{c}10(66,7) \\
5(33,3)\end{array}$ & $\begin{array}{l}30(100) \\
19(100)\end{array}$ & 0,424 \\
\hline $\begin{array}{l}\text { Kelompok Usia } \\
\text { - } 18-50 \text { tahun } \\
\text { - >50 tahun } \\
\text { Jenis Tumor }\end{array}$ & $\begin{array}{l}16(47,1) \\
18(52,9)\end{array}$ & $\begin{array}{c}13(86,7) \\
2(13,3)\end{array}$ & $\begin{array}{l}29(100) \\
20(100)\end{array}$ & 0,009 \\
\hline $\begin{array}{l}\text { - Low grade } \\
\text { - High grade }\end{array}$ & $\begin{array}{c}4(11,8) \\
30(88,2)\end{array}$ & $\begin{array}{l}6(40) \\
9(60) \\
\end{array}$ & $\begin{array}{l}10(100) \\
39(100)\end{array}$ & 0,033 \\
\hline
\end{tabular}

*Uji Chi-square.

Dari ketiga penanda hiperkoagulasi (Tabel 3), hanya sebagian kecil yang mengalami pemendekan aPTT dan PT, sementara sebagian besar mengalami peningkatan nilai D-dimer $(66,7 \%)$.

Subjek yang tidak mengalami hiperkoagulasi mempunyai kemungkinan hidup 3,97 (IK 95\%
Tabel 3. Profil Koagulasi pada Subjek $(n=49)$

\begin{tabular}{lc}
\hline \multicolumn{1}{c}{ Hemostasis } & n (\%) \\
\hline Pemendekan aPTT $(\mathbf{n}=\mathbf{4 8})$ & $10(20,8)$ \\
- Ya & $38(79,2)$ \\
- Tidak & \\
Pemendekan PT $(\mathbf{n}=\mathbf{4 1})$ & $0(0)$ \\
- Ya & $41(100)$ \\
- Tidak & $26(66,7)$ \\
Peningkatan D-dimer $(\mathbf{n}=\mathbf{3 9})$ & $13(33,3)$ \\
- Ya & \\
- Tidak & \\
aPTT: activated partial thromboplastin time; PT: prothrombin time. \\
1,05-14,99) kali pada 12 bulan pascaperawatan \\
secara bermakna dibandingkan pada subjek dengan \\
hiperkoagulasi (Tabel 4).
\end{tabular}

\section{PEMBAHASAN}

Sistem koagulasi adalah bagian dari jaringan pengatur yang mengintegrasikan sel parenkim dengan respons vaskular dan inflamasi. Sementara pembekuan darah adalah manifestasi aktivitas koagulasi yang paling banyak diteliti. Hal ini merupakan 'puncak gunung es' biologis dalam konteks tumor otak, bahwa lingkungan koagulan dapat memainkan peran patogenetik yang masih harus dikaji lebih lanjut. ${ }^{9}$

Sistem koagulasi pada tumor menjadi isu yang menarik untuk dibahas dan telah banyak studi dilakukan di Indonesia. Pada Departemen Neurologi RSCM, sudah ada beberapa studi yang mengevaluasi mengenai sistem koagulasi pada tumor SSP seperti yang dilakukan oleh Budikayanti dkk, Tunjungsari dkk, dan Aninditha dkk..$^{510-11}$

Penelitian ini mendapatkan 49 subjek astrositoma, namun belum memenuhi jumlah sampel minimal penelitian untuk membandingkan 2 proporsi yaitu 17 subjek pada kelompok dengan koagulopati dan 17 subjek pada kelompok tanpa koagulopati. ${ }^{12}$ Sementara itu, penelitian kesintasan menggunakan metode uji log-rank dan regresi Cox beserta kurva kesintasan Kaplan-Meier tidak mampu laksana karena membutuhkan sampel yang sangat besar, yaitu 2200 sampel dengan kejadian meninggal akibat VTE minimal sebanyak 713 berdasarkan perhitungan jumlah sampel dari 2 literatur. ${ }^{13-14}$

Subjek penelitian ini lebih banyak laki-laki dibanding perempuan, sama dengan Nayak dkk 
Tabel 4. Hubungan Hiperkoagulasi dengan Mortalitas $(n=49)$

\begin{tabular}{|c|c|c|c|c|}
\hline \multirow{3}{*}{ Hiperkoagulasi } & \multicolumn{2}{|c|}{ Kondisi Klinis } & \multirow{3}{*}{$\mathbf{p}$} & \multirow{3}{*}{$\begin{array}{c}\text { RR } \\
\text { (IK 95\%) }\end{array}$} \\
\hline & Meninggal & Hidup & & \\
\hline & n (\%) & n (\%) & & \\
\hline Ya & $18(52,9)$ & $16(47,1)$ & \multirow{2}{*}{0,009} & 3,97 \\
\hline Tidak & $2(13,3)$ & $13(86,7)$ & & $(1,05-14,99)$ \\
\hline
\end{tabular}

RR: risiko relatif; IK: interval kepercayaan.

mengenai studi tentang HGG yang jumlah laki laki lebih banyak 1,6 kali dibandingkan perempuan. ${ }^{1}$ Sesuai dengan hasil studi Central Brain Tumor Registry of the United States (CBTRUS) pada tumor otak primer, terdapat predominasi jenis kelamin tertentu terhadap jenis tumor primer. Perempuan terutama ditemukan pada meningioma $(81,8 \%)$ dan laki-laki pada astrositoma $(63,6 \%)$ secara signifikan. ${ }^{15}$

Menurut Bondy dkk, kejadian tumor otak primer di negara berkembang lebih banyak laki-laki dengan perbandingan laki-laki dan perempuan 3:2,1 per 100.000 penduduk. ${ }^{16}$ Hal ini berbeda dengan data dari Baglitbang RSKD tahun 2003-2007 yang menyatakan jumlah pasien yang datang berobat ke RSKD lebih banyak perempuan daripada laki-laki dengan perbandingan hampir 1:2. ${ }^{17}$

Sebagian besar subjek penelitian ini berusia 18-50 tahun, sesuai dengan populasi pada Budikayanti dkk. ${ }^{11}$ Demikian pula sebagian besar pasien kanker di RSKD berusia $>39$ tahun (75,86\%). Sebaran usia pasien kanker di RSKD menunjukkan peningkatan pada usia 25 tahun dengan puncak kasus usia 45 tahun $(15,41 \%)$ untuk perempuan dan 50 tahun $(13,14 \%)$ untuk laki-laki. Terjadinya penurunan jumlah kasus di Indonesia untuk perempuan menjadi 65 tahun dan laki-laki 67 tahun dipengaruhi oleh angka harapan hidup pada astrositoma.

High grade glioma $(79,6 \%)$ lebih banyak ditemukan dibandingkan LGG (20,4\%). Pada studi tentang glioblastoma, sekitar $60 \%$ adalah high-grade terutama pada usia dekade ke-5 sampai ke-7 yang insidennya meningkat seiring bertambahnya usia. ${ }^{1}$

Dalam penelitian ini ditemukan 69,4\% subjek mengalami hiperkoagulasi saat perawatan. Hasil ini lebih rendah dibandingkan Tehrani dkk bahwa 92\% pasien GBM ditemukan hiperkoagulasi, karena subjek penelitian ini bercampur antara low dan high grade, termasuk GBM, bukan hanya GBM. ${ }^{18}$

Terdapat kecenderungan koagulopati pada laki-laki $(58,8 \%)$ dibandingkan perempuan $(42,4 \%)$ meskipun tidak ada perbedaan proporsi yang signifikan $(p=0,424)$. Subjek berusia $>50$ tahun lebih banyak mengalami koagulopati dibandingkan subjek yang lebih muda $(52,9 \%$ vs $47,1 \%$; $=0,009)$. Hal ini sejalan dengan penelitian Budikayanti dkk yang menyatakan terdapat $72 \%$ subjek yang mengalami koagulasi intravaskular di rentang umur yang sama. ${ }^{11}$

Pada penelitian ini didapatkan frekuensi kejadian HGG disertai hiperkoagulasi lebih banyak bermakna dibanding LGG yang mengalami hiperkoagulasi. Hal ini sesuai dengan Eppy dkk bahwa kejadian hiperkoagulasi cenderung lebih tinggi pada kelompok pasien dengan keganasan/ stadium tinggi. ${ }^{19}$ Terdapat beberapa studi yang menghubungkan keganasan dengan profil koagulasi. Berdasarkan analisis pada seluruh subjek, didapatkan bahwa sebagian besar subjek mengalami koagulopati, yaitu memiliki minimal salah satu penanda koagulasi yang abnormal. ${ }^{5}$ Penelitian Amer terhadap 1874 pasien kanker, $16,4 \%$ diantaranya mengalami perkembangan trombosis selama hidup. ${ }^{20}$ Di RSKD, dilakukan pengkajian koagulopati dengan aPTT dan D-dimer pada pasien dengan astrositoma. Namun, belum ada pengkajian mengenai pembuluh darah yang mengalami trombosis. ${ }^{17}$

Hasil evaluasi terhadap subjek meninggal yang disertai hiperkoagulasi sebanyak 90\% mengalami hiperkoagulasi. Keadaan hiperkoagulasi lebih tinggi ditemukan pada subjek yang mengalami kematian dibandingkan pasien yang masih hidup pada 12 bulan pengamatan. Hal ini senada dengan Tehrani dkk bahwa keempat pasien $(100 \%)$ dengan astrositoma anaplastik yang baru didiagnosis yang disertai trombosis/koagulasi memiliki harapan hidup kurang 
dari 1 tahun, secara signifikan lebih pendek dari harapan hidup biasanya untuk penyakit ini. Sebagian besar penelitian menganalisis kelangsungan hidup subjek astrositoma anaplastik antara 24 dan 48 bulan. ${ }^{21}$ Dari 32 subjek anaplastik astrositoma tanpa disertai trombosis, hanya enam yang meninggal dalam waktu 1 tahun (19\%). ${ }^{19}$ Hal ini memperlihatkan bahwa koagulopati pada pasien dengan HGG dapat menyebabkan penurunan kesintasan.

Penelitian Semrad dkk pada 9.849 pasien astrositoma menyatakan bahwa terdapat 7,5\% insiden kumulatif VTE pada glioma maligna. Terdapat peningkatan rasio hazard kematian 2-tahun sebesar $30 \%$ pada pasien yang mengalami VTE. ${ }^{8}$ Sementara itu, Lim dkk menyatakan tidak ada perbedaan bermakna antara pasien GBM dengan atau tanpa VTE. Meskipun tidak ada perbedaan bermakna, median kesintasan pasien tanpa VTE dalam penelitian tersebut adalah 15,2 bulan dan dengan VTE 11,6 bulan. Nilai uji log-rank dalam penelitian tersebut juga mendekati kemaknaan $(\mathrm{p}=0,06) .{ }^{13}$ Dapat disimpulkan VTE pada pasien glioma dapat meningkatkan mortalitas.

Terdapat faktor-faktor lain yang memengaruhi mortalitas pada pasien dengan glioma. Komorbiditas seperti hipertensi, diabetes mellitus (DM), keganasan darah, sindrom metabolik, dan penyakit kronik lainnya dapat memengaruhi mortalitas dan status hiperkoagulasi pasien. Usia, status merokok, dan status pengobatan yang memengaruhi hemostasis berperan dalam kesintasan pasien. ${ }^{8,13}$ Namun, hal ini belum terlaksana dalam penelitian ini karena data retrospektif yang kurang memadai.

Tingkat oklusi pembuluh darah pada pasien GBM yang sangat tinggi di dalam tumor (di atas 90\%) dan berkorelasi dengan area karakteristik hipoksia dan nekrosis untuk keganasan tanpa memandang usia. Hingga saat ini belum diketahui trombosis intravaskular sebagai penyebab atau konsekuensi dari perubahan nekrotik. Mekanisme hubungan antara kejadian vasooklusi dengan trombosis vena perifer masih belum jelas. Meskipun mikrotrombus pada astrositoma anaplastik (yang berlanjut ke GBM) tidak memprediksi kejadian VTE, namun hal tersebut dapat berpengaruh pada kelangsungan hidup yang kurang baik, yang menunjukkan adanya hubungan antara koagulasi dan agresivitas penyakit. ${ }^{9}$

Penelitian ini merupakan penelitian pertama pengaruh koagulasi pada mortalitas pasien glioma yang mengklasifikasikan glioma berdasarkan derajatnya. Namun, terdapat keterbatasan jumlah sampel dan tidak semua pasien dilakukan pemeriksaan ketiga marker hemostasis. Selain itu, belum dilakukan analisis kesintasan menggunakan kurva KaplanMeier dan regresi Cox. Faktor-faktor lain seperti komorbiditas dan pengobatan yang berpengaruh terhadap hemostasis belum diinvestigasi. Metode analisis kesintasan dan faktor-faktor yang belum dimasukkan dalam penelitian ini dapat diteliti pada penelitian selanjutnya.

\section{KESIMPULAN}

Pasien astrositoma dengan hiperkoagulasi berisiko untuk mengalami kematian 3,97 kali lebih tinggi pada 12 bulan pascaperawatan dibandingkan tanpa hiperkoagulasi.

\section{DAFTAR PUSTAKA}

1. Nayak L, Reaedon DA. High grade gliomas. Continuum Life Long Learning in Neurology. 2017;23(6):1548-63.

2. Groot JF. High grade glioma. Continuum: American Academy of Neurology. 2015;21(2):332-44.

3. Aninditha T, Ranakusuma TAS. Tumor otak primer. Dalam: Aninditha T, Wiratman W, penyunting. Buku Ajar Neurologi. Jakarta: Penerbit Kedokteran Indonesia; 2017.

4. Khazatsin HA. Gambaran status metilasi gen promoter methylguanine deoksiribonucleic acid methyltrasferase pada Astrositoma dan faktor-faktor yang mempengaruhi. Jakarta: Universitas Indonesia; 2014.

5. Tunjungsari D. Perbandingan profil koagulasi pada tumor otak primer dan tumor otak sekunder. Jakarta: Universitas Indonesia; 2016.

6. Edwin NC, Elson P, Ahluwalia MS, Khorana AA. Venous thromboembolism in patients with glioblastoma: Risk factors and prognostic importance. J Clin Oncol. 2018;33(Suppl 15).

7. Renni MJP, Cerqueira MH, Trugilho IA, Junior MLCA, Marques MA, Koch HA. Mechanisms of venous thromboembolism in cancer: A literature review. J Vasc Bras. 2016;16(4):308-13.

8. Semrad TJ, O'Donnell R, Wun T, Chew H, Harvey D, Zhou H, dkk. Epidemiology of venous 
thromboembolism in 9489 patients with malignant glioma. J Neurosurg. 2007;106(4):601-8.

9. D'Asti E, Fang Y, Rak J. Brain neoplasms and coagulation-lessons from heterogeneity. Rambam Maimonides Med J. 2014;5(4):e0030.

10. Aninditha T. Peran hemostasis pada pertumbuhan tumor. Neurona. 2012;29(3).

11. Budikayanti A, Ranakusuma TAS, Bustami M, Prihartono J. Penilaian status koagulasi dan profil karotis sebaggai komplikasi serebrovaskular pada tumor susunan saraf pusat. Neurona. 2009;26(2).

12. Sastroasmoro S, Ismael S. Dasar-dasar metodologi penelitian klinis. Edisi ke-5. Jakarta: Sagung Seto; 2014.

13. Lim G, Ho C, Roldan Urgoti G, Leugner D, Easaw J. Risk of venous thromboembolism in glioblastoma patients. Cureus. 2018;10(5):e2678.

14. Schoenfeld DA. Sample-size formula for the proportional-hazards regression model. Biometrics. 1983;39(2):499-503.

15. Burkhard C, Di Patre PL, Schuler D, Schuler G, Yasargil MG, Yonekawa $\mathrm{Y}$, dkk. A populationbased study of the incidence and survival rates in patients with pilocytic astrocytoma. J Neurosurg. 2003;98(6):1170-4.

16. Bondy ML, Scheurer ME, Malmer B, BarnholtzSloan JS, Davis FG, Il'yasova D, dkk. Brain tumor epidemiology: Consensus from the Brain Tumor Epidemiology Consortium. Cancer. 2008;113(7 Suppl):1953-68.

17. Registry RS Kanker Dharmais. Kementerian Kesehatan Republik Indonesia. 2012.

18. Kurniawan A. Patogenesis, diagnosis dan penatalaksaan tromboemboli vena pada kanker. Indonesian Journal of Cancer. 2013;7(3).

19. Eppy, Harsal A, Amin Z. Hypercoagulation among non-small cell lung carcinoma patiens. Majalah Keodkteran Indonesia. 2007;57(2).

20. Amer MH. Cancer-associated thrombosis: Clinical presentation and survival. Cancer Manag Res. 2013;5:165-78.

21. Tehrani M, Friedman TM, Olson JJ, Brat DJ. Intravascular thrombosis in central nervous system malignancies: A potential role in astrocytoma progression to glioblastoma. Brain Pathol. 2008;18(2):164-71. 